\title{
Effect of Strain-Temperature History on the Flow and Fracture of Ingot Iron at Low Temperatures
}

\author{
Glenn W. Geil and Nesbit L. Carwile
}

\begin{abstract}
The effect of the strain-temperature history of ingot iron on the true stress-strain relationship for tensile specimens extended at temperatures ranging from $-196^{\circ}$ to $+100^{\circ} \mathrm{C}$ is reported. Specimens of ingot iron in various initial conditions were extended to a specified strain at a selected temperature and subsequently extended to fracture at a different temperature. The deviation of the true stress-strain values for the second stage of these tests from corresponding values for a single-stage test generally increase at a decreasing rate as the prestrain of the specimen increases.

The "rheotropic embrittlement" and work hardening (strain hardening plus strain aging) vary with the heat treatment and prestrain history of the ingot iron. The brittleness at or below $-78^{\circ} \mathrm{C}$ of normalized or hot-rolled ingot iron is partially curable by prestraining in tension at room temperature. However, prestraining in tension of annealed ingot iron at room temperature decreases the ductility retained at $-154^{\circ}$ and $-196^{\circ} \mathrm{C}$. The predominance of strain aging at the higher temperatures and strain hardening at the lower temperatures causes the total work hardening of the specimen during deformation to maximum load to increase as the test temperature is either increased or decreased from about $-120^{\circ} \mathrm{C}$.
\end{abstract}

\section{Introduction}

In recent years several investigations $\left[\begin{array}{lll}1 & \text { to } & 11\end{array}\right]^{2}$ on the mechanical properties of metals at low temperatures have shown conclusively that the true stress-strain relationship of metals and alloys extended in tension depends on the strain-temperature history, as well as on the instantaneous values of strain, strain rate, and test temperature. In most of these investigations very little information was reported on the part played by strain aging during the prior history of the specimen, as strain aging was not pronounced in most of the metals studied. A previous investigation [10] at the Bureau showed that strain aging affected the true stress-strain relationship of ingot iron specimens extended in tension at slightly elevated temperatures and even at some subzero temperatures $\left(-120^{\circ}\right.$ to $\left.+100^{\circ} \mathrm{C}\right)$. Within the temperature range, $-196^{\circ}$ to $+100^{\circ} \mathrm{C}$, of that investigation the strain hardening of ingot iron increased with a decrease in temperature, whereas the strain aging decreased with a decrease in temperature. Therefore, work hardening ${ }^{3}$ of ingot iron may either increase or decrease with increase in testing temperature, depending upon the relative magnitude of the changes in strain hardening and strain aging with variation in temperature.

The rate of strain hardening of ingot iron is influenced by the mechanism of deformation. The spacing of the slip zones within the crystals and also the number of slip bands in a zone vary with the temperature of deformation of the metal. These factors are believed to be directly associated with the increase in the rate of strain hardening of the metal with de-

1 This investigation was sponsored (in part) by the Ordnance Department, U. S. Army, through the Ordnance Corps, Watertown Arsenal.

2 Figures in brackets indicate the literature references at the end of this paper

3 As used in this paper the term "work hardening" relates to the increase in true stress with true strain and is the combined effect of strain hardening an strain aging. The term "strain hardening" refers to that portion of the hardening or strengthening of the metal during plastic deformation that is not time dependent and occurs concurrently with strain, whereas the term "strain aging" refers to that portion of the hardening or strengthening occurring during or subsequent to plastic deformation that is time dependent and occurs as a result of previous strain and not concurrent strain. crease in testing temperature. Moreover, as previously reported [10], considerable deformation by twinning was observed in specimens of ingot iron slowly extended in tension at temperatures below about $-120^{\circ} \mathrm{C}$. The extent of the twinning during the tension test increased greatly as the temperature was lowered from about $-120^{\circ}$ to $-196^{\circ} \mathrm{C}$. The influence of this factor on the rate of strain hardening of the iron may be considerable.

The purpose of the present investigation was to obtain additional information on the influence of the strain-temperature history, and especially the effect of strain aging, on some of the tensile properties and the true stress-strain relationship for specimens of ingot iron subsequently tested in tension.

\section{Material}

The material used in this investigation was ingot iron in the conditions as annealed, hot-rolled, quenched and tempered, normalized, and cold-drawn. A detailed description of this material was reported in a previous paper [10]. The principal chemical constituents (in percent by weight) other than iron are as follows: Carbon, 0.02 ; manganese, 0.02 ; phosphorus, 0.005 ; sulfur, 0.018 ; silicon, 0.002 ; copper, 0.10 ; oxygen, 0.058 ; nitrogen, 0.002 ; and hydrogen, 0.0005 . This iron was prepared from a single melt and was furnished by the manufacturer in the conditions as hot-rolled and as cold-drawn to 14- and 24-percent reductions of area. The heat treatments applied to the ingot iron in this laboratory are summarized in table 1.

Cylindrical tensile specimens with a 2 -in. gage length were used. The reduced section was gradually tapered from each end; the diameter (0.438 in.) at the midsection of the gage length was about 0.003 in. less than at at each end. The specimens were finished to the final dimensions by grinding and polishing in the axial direction. The ends of the specimen were machined with $3 / 4$ in. $\times 10$ threads, and 
the shoulder fillets were machined to a radius of 0.75 in.

TABLE 1. Heat treatment of ingot iron ${ }^{1}$

\begin{tabular}{|c|c|c|c|c|}
\hline Designation & $\begin{array}{l}\text { Diam- } \\
\text { eter of } \\
\text { rod }\end{array}$ & $\begin{array}{l}\text { Tem- } \\
\text { pera- } \\
\text { ture }\end{array}$ & Time & Remarks \\
\hline $\begin{array}{l}\text { Annealed.......... } \\
\text { Normalized........ } \\
\text { Quenched and tem- } \\
\text { pered. }\end{array}$ & $\begin{array}{r}.875 \\
2.500\end{array}$ & $\begin{array}{c}\circ F \\
1,750 \\
\left\{\begin{array}{l}1,750 \\
1,700 \\
1,330\end{array}\right.\end{array}$ & $1^{1 / 2}$ & $\begin{array}{l}\text { Furance-cooled to } 800^{\circ} \mathrm{F} \\
\text { in } 20 \mathrm{hr} \text {, then air- } \\
\text { cooled. } \\
\text { Air-cooled. } \\
\text { Quenched in iced brine. } \\
\text { Furnace cooled to } 100^{\circ} \mathrm{F} \\
\text { in } 45 \mathrm{hr} \text {. }\end{array}$ \\
\hline
\end{tabular}

All specimens were prepared from hot-rolled rods.

Specimens machined to approximate $1 / 2$ in. in diameter in reduced section and $3 / 4$ in. in diameter in shoulders prior to heat treatment.

\section{Method of Investigation}

The specimens were extended in tension in a pendulum hydraulic testing machine of 50,000-lb capacity. The specimens, except those tested at room temperature, were fully immersed in an appropriate liquid maintained at the desired temperature. The loading was so controlled that the rate of reduction of area of the specimen, beyond the region of initial yielding, was maintained at approximately 1 percent/minute. Measurements of the diameter of the specimen throughout the course of each test were made by means of a specially designed reduction of area gage [12]. Changes in diameter of a specimen were measured by this instrument with an accuracy of \pm 0.0001 in. A detailed description of the testing equipment and the method of maintaining the desired temperature is given in previous papers $[10,12]$.

TABLE 2. Two-stage test conditions

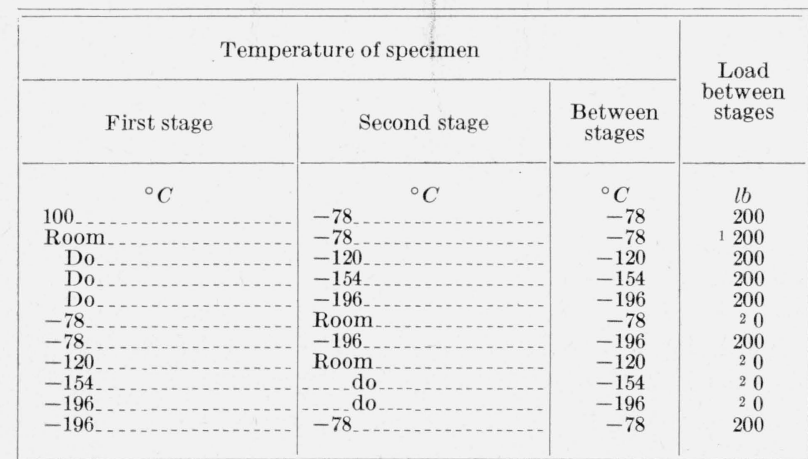

1 Two special tests also were made in which the load obtained at the end of the first stage was maintained between stages.

2 Specimen was removed from the testing machine between stages.

In the present investigation, a specimen was extended at a selected temperature to a specified strain value and subsequently extended to fracture at a different temperature. In general, the specimen was kept in the testing machine between stages under a small load of approximately $200 \mathrm{lb}$ to maintain the alinement of the specimen in the testing machine. However, when the second stage of a two-stage test was at room temperature, the specimen was removed from the testing machine between stages so that the adapters and adjacent portions of the head and base of the testing machine could be quickly brought to room temperature. Moreover, in two special tests the load attained at the end of the first stage was maintained on the specimen in the machine between stages. The specimens were kept cool between stages, as reported in table 2 , in order to minimize strain aging during this period. Usually the second stage was begun approximately $\frac{1}{2} \mathrm{hr}$ after completion of the first stage.

\section{Results and Discussion}

True stress-strain data obtained in two-stage tension tests on ingot-iron specimens at selected temperatures ranging from $-196^{\circ}$ to $+100^{\circ} \mathrm{C}$ are summarized in figures 1 and 2 , and 4 to 9 . True stressstrain curves obtained in the single-stage tension tests, reported in a previous paper [10], are included in these graphs as broken-line curves, and the upper end of these curves represents initial fracture. The true stress-strain values representing the completion of the first stage and the data obtained in the second stage of the two-stage tension tests are shown. The data obtained in the first stage of the test conforms to the curve representing the corresponding deformation in a single-stage test and these values are, in most cases, not plotted in these graphs. The true stress-strain values during the unloading and the initia! part of the reloading also are not shown in some of the figures. The true-stress and true-strain values attained at the fracture area of the specimen at the initiation of fracture are designated in this paper as the fracture stresses and fracture strains, respectively, and, except for certain specifically designated cases, they are represented by the final true stress-strain values plotted in figures 1 and 2 , and 4 to 9 .

\subsection{Annealed Ingot Iron}

In order to determine the direct effect of a reduction of load in a tension test for a short time on the subsequent true stress-strain values, a special tension test was made at a single temperature (room temperature) on a specimen of annealed ingot iron. The deformation of this specimen was carried out in four stages and included an initial loading to a selected extension, an unloading to $200 \mathrm{lb}$ for a period of 5 minutes, followed by a reloading to a second selected extension, then repeating the procedure until a total of four stages had been completed. As shown in figure 1, the true stress-strain values for this fourstage test generally coincided with those of a singlestage test made on a specimen of annealed ingot iron at room temperature, except for the true stresses at the initial strains of the second, third, and fourth stages; these true stresses were slightly higher than the corresponding stresses in a single-stage test. Apparently, the combined effect of the strain aging at room temperature during the 5-minute periods between stages and the unloading and reloading was sufficient to increase the true-stress values at the initial yielding in the last three stages but was not sufficient to affect appreciably the subsequent truestress values. It is believed that, in general, short 


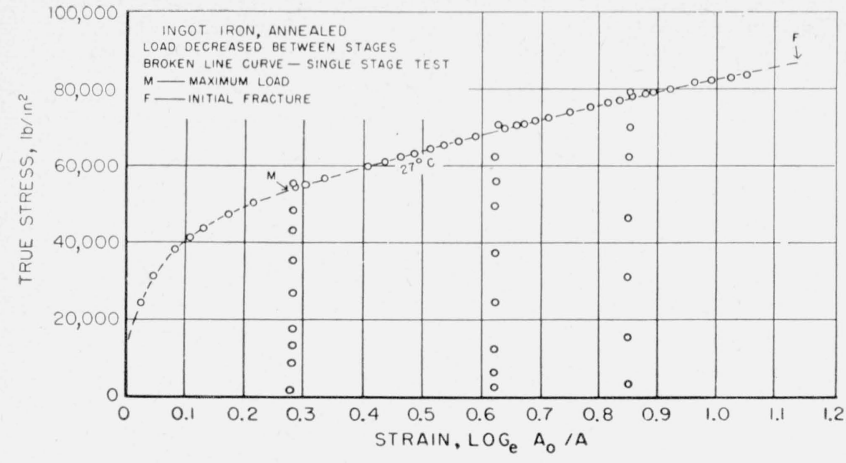

FIGURE 1. True stress-strain values obtained with an annealed ingot-iron specimen that was extended in a four-stage tension test at room temperature.

interruptions of this type in a tension test with ingot iron at room or lower temperatures, in which the temperature of the specimen is held constant during the test, have very little effect on the true stressstrain values, except those during the initial yielding in the next stage of the test.

Four specimens of annealed ingot iron were extended in tension at room temperature to specified strains (indicated as short vertical bars on the $27^{\circ} \mathrm{C}$ curve in fig. 2), and subsequently extended to fracture at $-196^{\circ} \mathrm{C}$. As shown in figure 2 , these specimens exhibited very little ductility in the second-stage test, although a specimen of annealed ingot iron that was extended in a single-stage test at $-196^{\circ} \mathrm{C}$ deformed to a strain of about 0.05 before initial fracture. In the two tests, in which the deformation of the specimen in the first stage of the test at room temperature was greater than the maximum load strain, the specimens fractured in the second-stage test without any appreciable plastic deformation, and the fractures occurred at the shoulder of the

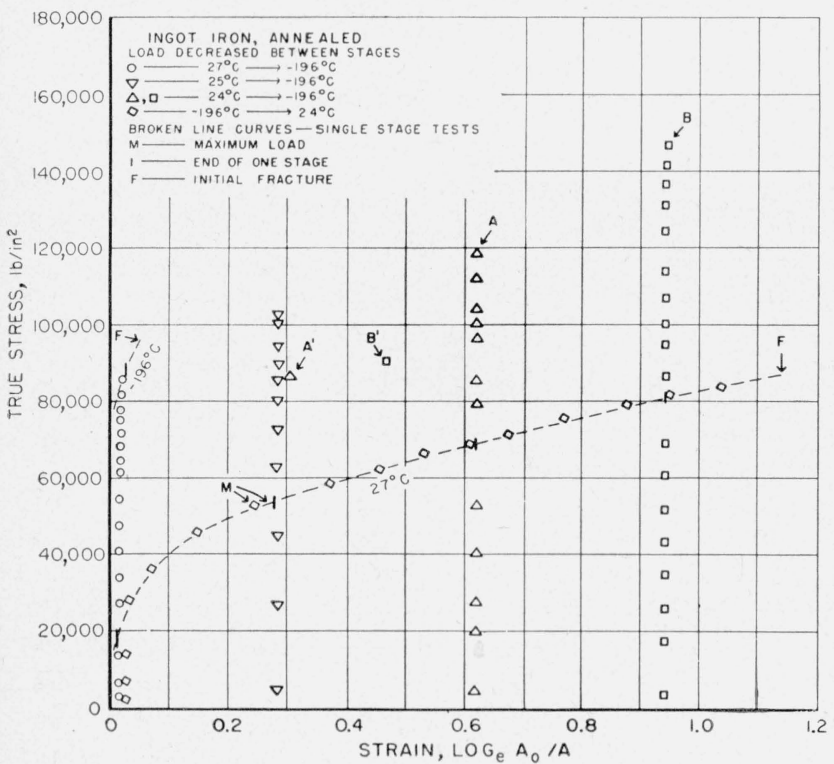

Figure 2. True stress-strain values obtained with annealed ingot-iron specimens that were extended in two-stage tension tests at room temperature and $-196^{\circ} \mathrm{C}$.

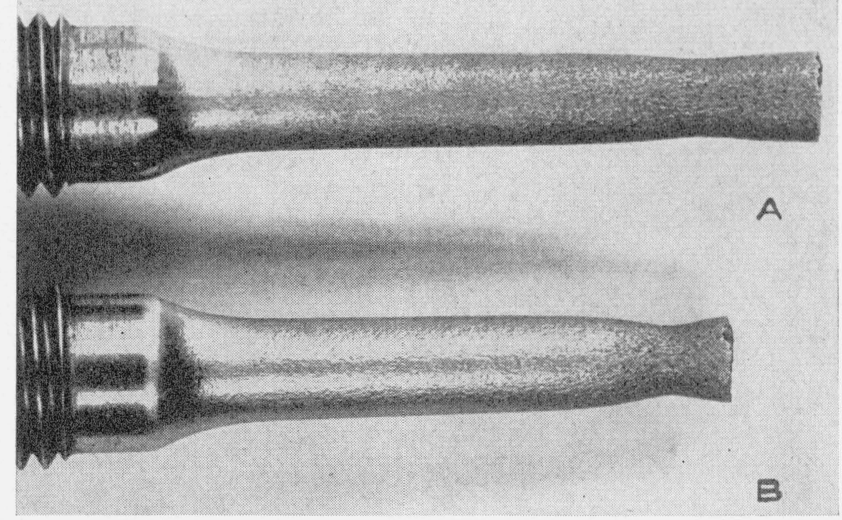

Figure 3. Portions of two specimens of annealed ingot iron that were extended in tension at room temperature to strains beyond maximum load and subsequently fractured in tension at $-196^{\circ} \mathrm{C}$

A, True strain of 0.62 at room temperature; B, true strain of 0.94 at room temperature

necked section (fig. 3). The final true stress-strain values as determined by the final load and minimum cross-sectional-area measurements for these specimens are designated as points A and B in figure 2 . As the fractures did not occur at the minimum cross section of the specimens, the stress values represented by points A and B are not fracture stresses; these data indicate only that the fracture stresses at $-196^{\circ} \mathrm{C}$ for the position of the minimum section of the specimens of annealed ingot iron that were extended in tension at room temperature to these designated strain values were greater than the indicated stress values. The fracture stresses and fracture strains at $-196^{\circ} \mathrm{C}$ of these specimens under the multiaxial stress conditions existing at the position of the actual fracture in the shoulder of the necked section are shown by the corresponding points $\mathrm{A}^{\prime}$ and $\mathrm{B}^{\prime}$ in figure 2 . It may be noted that the fracture stresses at $-196^{\circ} \mathrm{C}$ in the shoulder portion of the neck of the specimens are lowered to values below that of the tension specimen fractured at $-196^{\circ} \mathrm{C}$ in uniaxial tension after extension at room temperature to maximum load. This may be attributed to the influence of biaxial compressive stresses at these positions.

As the ductility of specimens of annealed ingot iron in single stage tests at $-196^{\circ} \mathrm{C}$ was small (strain of approximately 0.05 ), v ery little information could be obtained on the effect of prior strain at $-196^{\circ} \mathrm{C}$ of specimens of annealed ingot iron on their tensile properties at room temperature. The data obtained on a specimen extended in the first stage of the test at $-196^{\circ} \mathrm{C}$ to a strain of about 0.02 and then extended to fracture in the second-stage test at room temperature indicated that the total work hardening during the deformation at $-196^{\circ} \mathrm{C}$ was approximately equivalent to the total work hardening of a specimen deformed the same amount at room temperature; the true stress-strain values obtained in the second stage of the test approximately coincided with the corresponding values ob- 
tained in the single-stage test at room temperature (fig. 2). Thus the increase in the strain hardening at $-196^{\circ} \mathrm{C}$ above that at room temperature was approximately equal to the strain aging at room temperature.

A specimen of annealed ingot iron was prestrained in tension at room temperature to maximum load and then extended to fracture at $-154^{\circ} \mathrm{C}$. This specimen retained considerably less ductility and hence had a lower fracture stress than a specimen extended to fracture in a single-stage test at $-154^{\circ} \mathrm{C}$, as shown in figure 4. The strain during the second stage of this test was very small in comparison with the strain beyond maximum load in the single-stage test at $-154^{\circ} \mathrm{C}$. The strain aging of the specimen during the deformation at room temperature apparently made the specimen quite brittle at the lower temperature.

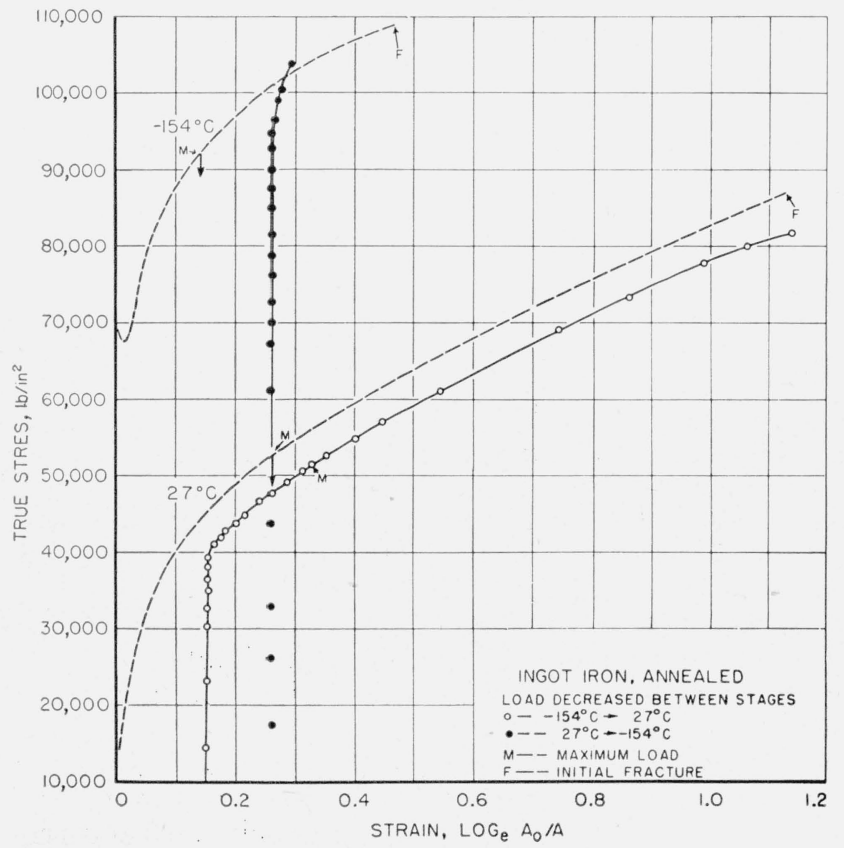

FIGURE 4. True stress-strain values obtained with annealed ingot-iron specimens that were extended in two-stage tension tests at room temperature and $-154^{\circ} \mathrm{C}$.

An annealed ingot-iron specimen was prestrained in tension at $-154^{\circ} \mathrm{C}$ to maximum load and then extended to fracture at room temperature. The true stress-strain curve for the second stage of this test (fig. 4) is considerably below the corresponding part of the curve for a single-stage test with a specimen at room temperature, and thus the total work hardening of the specimen during the first stage of the test at $-154^{\circ} \mathrm{C}$ was less than that of a specimen deformed to the same strain at room temperature. Strain aging in specimens of ingot iron during deformation in tension at $-154^{\circ} \mathrm{C}$ is very slight [10]. Moreover, strain hardening increases with a lowering of the test temperature from room temperature to $-154^{\circ} \mathrm{C}$. The data in figure 4 , therefore, indicate that the strain aging of the iron at room temperature was much greater than was the increase in strain hardening with decrease from room temperature to $-154^{\circ} \mathrm{C}$.

In order to determine the specific influence of the degree of the prestraining of annealed ingot-iron specimens at one temperature on their deformation characteristics at another temperature, two series of two-stage tests were made. One series of specimens was prestrained in tension at room temperature to different strains and subsequently extended to fracture at $-78^{\circ} \mathrm{C}$. The true stress-strain data for these tests are summarized in figure 5. The true stress-strain curves for the second stage of these tests are above the corresponding portion of the curve for a single-stage test at $-78^{\circ} \mathrm{C}$. Another series of specimens was prestrained in tension at $-78^{\circ} \mathrm{C}$ to different strains and subsequently extended to fracture at room temperature. The true stressstrain curves (fig. 5) for the second stage of each

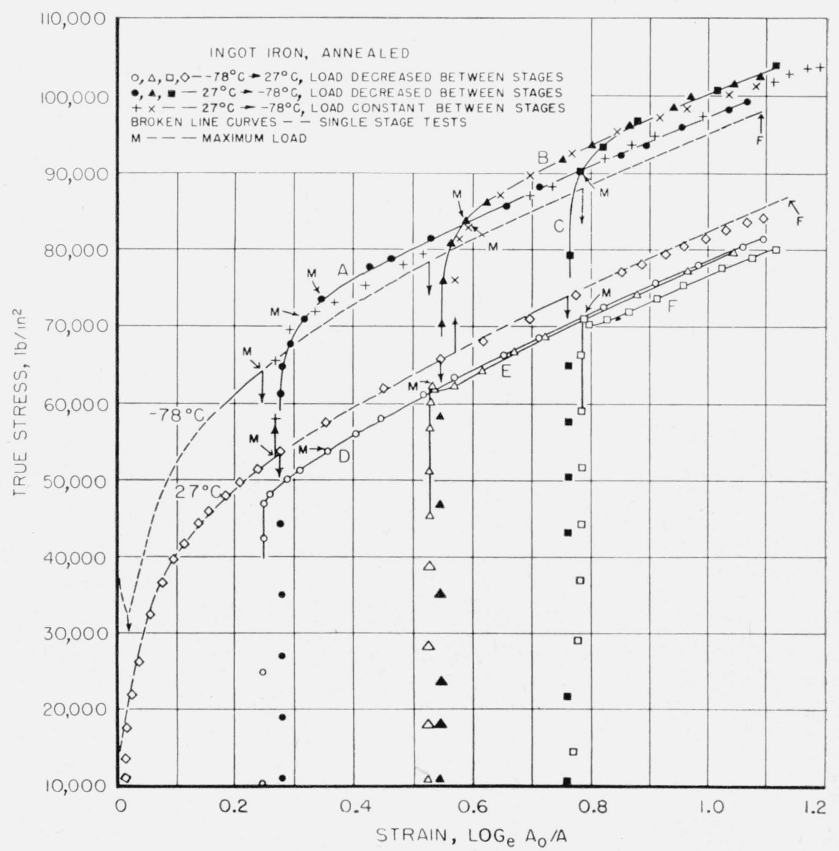

Figure 5. True stress-strain values obtained with annealed ingot-iron specimens that were extended in two-stage tension tests at room temperature and $-78^{\circ} \mathrm{C}$.

of these tests, except for the specimen prestrained only to the lower yield, are below the corresponding portion of the curve for a single-stage test at room temperature. The curve for the second-stage test of the specimen prestrained to the lower yield coincided with the curve for the single-stage test at room temperature. The combined effect of the strain hardening and strain aging during the prestraining at $-78^{\circ} \mathrm{C}$ in this test was equivalent to the combined effect of the strain hardening and strain aging during the deformation to the same strain at room temperature. In general, the deviation of the true stress-strain curve for the second stage of a twostage test from the curve for a single-stage test at the same temperature (fig. 5) increases at a decreasing rate as the amount of prestraining in the first stage increases. The above data indicate that 
the strain aging of a specimen of annealed ingot iron at any strain during deformation in tension at a constant temperature varies with the strain; the strain aging at any strain depends greatly upon the amount of the prior strain aging of the specimen.

In order to determine the effect of maintaining a relatively high stress on the specimen between test stages, two special tests were made in which the load attained at the end of the first stage was maintained on the specimen until the beginning of the second stage. The true stress-strain values obtained in these tests (fig. 5) show no significant deviation from the true stress-strain curves of corresponding twostage tests in which the load was reduced to about $200 \mathrm{lb}$ between stages. The retained ductility at $-78^{\circ} \mathrm{C}$ of the specimen prestrained at room temperature to a strain of about 0.26 with no reduction of the load between stages was slightly greater than that of the specimen prestrained at room temperature to approximately the same amount, with the load reduced to $200 \mathrm{lb}$ between stages. This small difference in ductility, however, is not believed to be significant. In general, the strains to fracture of the specimens in the twostage tests summarized in figure 5 were approximately the same at both temperatures and also were about the same as those for the single-stage tests at these temperatures.

Ripling and Baldwin in reporting on the phenomenon they called the "rheotropic embrittlement" of steel [11] concluded that a large part of the deficiency in ductility of annealed steels at low temperatures is rheotropic and can be removed by prestraining under more ductile conditions at a higher temperature. The data obtained in the present investigation on annealed ingot iron, however, indicate that the low-temperature embrittlement of this material is not rheotropic in the manner proposed by Ripling and Baldwin; prestraining of the annealed ingot iron at room temperature reduced, rather than increased, the ductility retained either at $-154^{\circ}$ or $-196^{\circ}$ C. The embrittlement due to strain aging during the prestraining of the specimens at room temperature, is believed to be the main cause for the loss in the retained ductility at $-154^{\circ}$ or $-196^{\circ} \mathrm{C}$. Another factor that probably has considerable influence on the retained ductility is a decrease in the degree of deformation twinning occurring at the low temperature following a prestraining at room temperature. This latter factor is being studied in some detail and will be discussed in a separate report.

\subsection{Normalized Ingot Iron}

The true stress-strain data for two normalized ingot-iron specimens that were extended in tension in two-stage tests at room temperature and $-78^{\circ} \mathrm{C}$ are presented in figure 6 . The effect of the prestraining in the first stage of the tension test on the total work hardening of these specimens was similar to that already described for two-stage tests with annealed ingot iron at these temperatures. The ductility, however, was affected quite differently. As

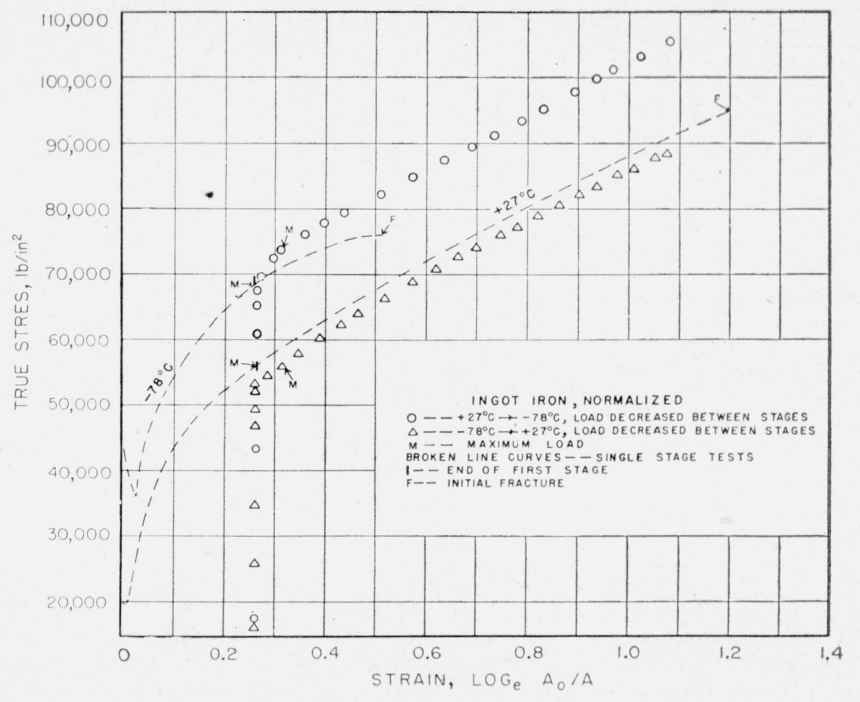

FIGURE 6. True stress-strain values obtained with normalized ingot-iron specimens that were extended in two-stage tension tests at room temperature and $-78^{\circ} \mathrm{C}$.

illustrated in figures 25 and 26 of the previous paper [10], the ductility of normalized ingot iron, and to a lesser degree that of hot-rolled ingot iron, extended to fracture in single-stage tests was much lower at $-78^{\circ} \mathrm{C}$ than at room temperature. The strain to fracture of ingot iron in the annealed, quenched, and tempered, or cold-drawn conditions, however, was nearly the same at room temperature and at $-78^{\circ} \mathrm{C}$. The decrease in the ductility at $-78^{\circ} \mathrm{C}$ of the ingot iron in the normalized or hot-rolled condition may be associated with a greater amount of carbon and nitrogen initially retained in solid solution in these conditions than in the other conditions. The data for the two-stage tests of the normalized ingot iron (fig. 6) show that the iron in this condition apparently is subject to rheotropic embrittlement in the manner proposed by Ripling and Baldwin; prestraining the specimen at room temperature to just beyond the maximum load increased greatly the ductility retained at $-78^{\circ} \mathrm{C}$, as indicated by the fracture strain of approximately 1.1 for this two-stage test and the fracture strain of approximately 0.5 for the single stage test at $-78^{\circ} \mathrm{C}$. Prestraining a specimen at $-78^{\circ} \mathrm{C}$ to the maximum load decreased the ductility retained at room temperature. Apparently, the rheotropic embrittlement of the specimen during the prestraining at $-78^{\circ} \mathrm{C}$ was not completely removed by the subsequent deformation at room temperature.

\subsection{Quenched and Tempered Ingot Iron}

The data obtained in two-stage tension tests with specimens of quenched and tempered ingot iron are summarized in figure 7 . These results indicate that the effect of prestraining specimens at room temperature and $-78^{\circ} \mathrm{C}$ is approximately the same as that described previously for specimens of the annealed ingot iron; the difference in magnitude of strain aging at $-78^{\circ} \mathrm{C}$ and room temperature was greater than the difference in strain hardening at these tempera- 


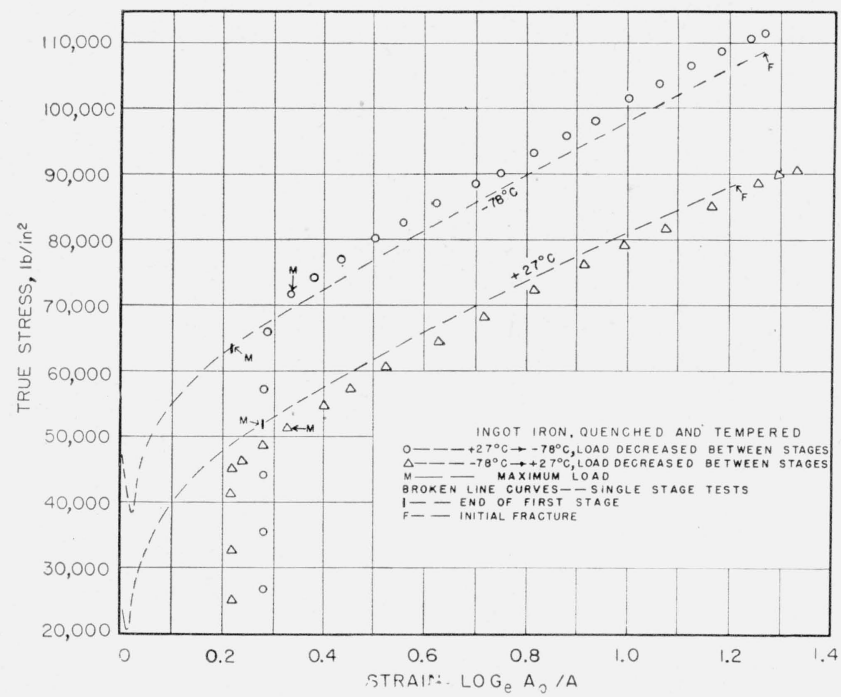

Figure 7. True stress-strain values obtained with quenched and tempered ingot-iron specimens that were extended in two-stage tension tests at room temperature and $-78^{\circ} \mathrm{C}$.

tures, and the predominating effect of the strain aging resulted in greater total work hardening during the prestraining at room temperature than at $-78^{\circ} \mathrm{C}$. The ductility retained by the specimens in the second stage of the tests was not affected appreciably by the difference in the prior strain histories.

\subsection{Hot-Rolled Ingot Iron}

As the ductility of the hot-rolled ingot iron was considerable, even at low temperatures (fracture strain of approximately 0.3 at $-196^{\circ} \mathrm{C}$ ), specimens were prestrained in tension at temperatures ranging from $-196^{\circ}$ to $+100^{\circ} \mathrm{C}$ and then extended to fracture at different temperatures. The true stressstrain data for these tests and the curves obtained in single-stage tests at these temperatures are summarized in figure 8. Prestraining specimens approximately to maximum load at $-196^{\circ},-120^{\circ}$, or $-78^{\circ} \mathrm{C}$ had little specific effect on the ductility retained in the second stage of the tests at room temperature. The deformation under ductile conditions at room temperature apparently removed any rheotropic embrittlement that may have occurred during the prestraining at low temperature. As the work hardening of a specimen of ingot iron during deformation at $-196^{\circ} \mathrm{C}$ is mainly strain hardening, and as strain hardening increases with decrease in temperature from $-78^{\circ}$ to $-196^{\circ} \mathrm{C}$, the data showing equal work hardening of the hot-rolled ingot-iron specimens during the prestraining at $-78^{\circ}$ and $-196^{\circ} \mathrm{C}$ (fig. 8) indicate that strain aging occurred to a considerable extent during the prestrain of the specimen at $-78^{\circ} \mathrm{C}$. The work hardening during the prestraining in tension at $-120^{\circ} \mathrm{C}$ of a specimen approximately to maximum load was the least for this series of tests and resulted in the greatest lowering of the points representing the true stress-strain values for the second stage of the tests from the curve for the single-stage test at room temperature. The strain aging of hot-rolled ingot iron during deformation was very much less at $-120^{\circ} \mathrm{C}$ than at $-78^{\circ} \mathrm{C}$. However, as shown in figure 12 of a previous investigation [10], strain aging occurs to an appreciable extent in specimens of hot-rolled ingot iron deformed in tension at $-120^{\circ} \mathrm{C}$ and at $-138^{\circ} \mathrm{C}$.

Although the total work hardening (mainly strain hardening) of a specimen during prestraining approximately to maximum load at $-196^{\circ} \mathrm{C}$ was about equal to the total work hardening (strain hardening plus strain aging) of a specimen deformed to the same strain at $-78^{\circ} \mathrm{C}$, the resulting rheotropic properties of these two specimens were different. The points representing the true stress-strain values for the second-stage test at $-78^{\circ} \mathrm{C}$ of the specimen prestrained at $-196^{\circ} \mathrm{C}$ gradually rise above the corresponding portion of the curve for the specimen extended in the single-stage test at $-78^{\circ} \mathrm{C}$ (fig. 8). These data indicate that the strain aging during the deformation from maximum load to fracture of the former specimen was much greater than that of the latter specimen. As the fracture strains of the above specimens were about equal, the deformation during the second-stage test at $-78^{\circ} \mathrm{C}$ apparently removed most of the low-temperature embrittlement that had occurred during the prestraining at $-196^{\circ} \mathrm{C}$.

The specimen of hot-rolled ingot iron that was prestrained in tension at room temperature to a small strain of approximately 0.03 , broke in the threads during the second-stage test at $-196^{\circ} \mathrm{C}$ without any appreciable plastic deformation of the specimen.

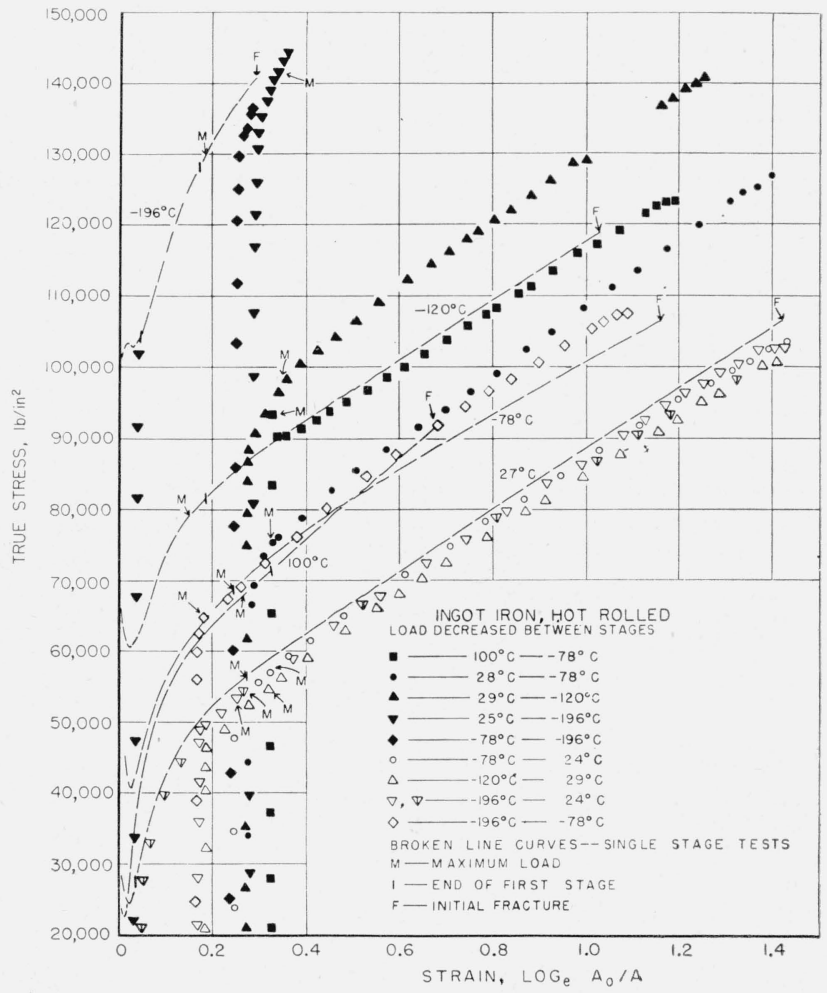

FIGURE 8. True stress-strain values obtained with hot-rolled ingot-iron specimens that were extended in two-stage tension tests at different temperatures. 
The final value plotted in figure 8 for this test does not represent the fracture stress and fracture strain at $-196^{\circ} \mathrm{C}$ of the prestrained metal. As the yield stress of this specimen at $-196^{\circ} \mathrm{C}$ was at least equal to or greater than that represented by the final plotted value, and as this point lies approximately on the true stress-strain curve for the single-stage tension test on hot-rolled ingot iron at $-196^{\circ} \mathrm{C}$, the prestraining of the specimen at room temperature, apparently did not decrease the stress necessary for continued deformation of the metal at $-196^{\circ} \mathrm{C}$.

Specimens of hot-rolled ingot iron that were prestrained in tension at room temperature approximately to maximum load and then extended to fracture at $-78^{\circ},-120^{\circ}$, and $-196^{\circ} \mathrm{C}$, exhibited strain-aging effects similar to those described above for the specimens prestrained at low temperatures. However, a difference was observed in the effect of the prestraining at room temperature on the ductility retained at lower temperatures, and this should be pointed out. Prestraining at room temperature approximately to the maximum load improved the ductility retained by the specimen at the lower temperature and the fracture strains of the specimens in the two-stage tests were greater than those of the specimens fractured in the single-stage tests at the same low temperatures (fig. 8). Thus, the rheotropic embrittlement of the hot-rolled ingot iron during the second stage of these tests was reduced by the prestraining under the more ductile conditions at room temperature.

A specimen of hot-rolled ingot iron was prestrained in tension at $100^{\circ} \mathrm{C}$ to a strain slightly beyond the maximum load and then extended to fracture at $-78^{\circ} \mathrm{C}$. The strain aging of this specimen during the deformation at $100^{\circ} \mathrm{C}$ was much greater than that of specimens deformed at room temperature, and is indicated by the position of the true stressstrain values in figure 8 for the second stage of the test; the elevation of these points above the curve for the single-stage test at $-78^{\circ} \mathrm{C}$ is much greater than that for the specimen prestrained at room temperature. The fracture strain of the specimen prestrained at $100^{\circ} \mathrm{C}$ was about equal to that of the specimen extended to fracture in a single-stage test at $-78^{\circ} \mathrm{C}$. However, it was considerably less than that of the specimen prestrained at room temperature and extended to fracture at $-78^{\circ} \mathrm{C}$. The embrittlement of the specimen by the great amount of strain aging during the deformation at $100^{\circ} \mathrm{C}$ apparently was about equal to the rheotropic embrittlement during the deformation of a specimen to the same strain in the single-stage test at $-78^{\circ} \mathrm{C}$.

The true stress-strain data for hot-rolled ingot iron specimens (fig. 8) indicate that the strain hardening is the predominating factor affecting the variation of the total work hardening with temperature at temperatures below $-120^{\circ} \mathrm{C}$, whereas the strain aging is the predominating factor affecting the total work hardening at temperatures above $-120^{\circ} \mathrm{C}$.

As described earlier, the ductility of specimens of normalized ingot iron was much less at $-78^{\circ} \mathrm{C}$ and at lower temperatures than at room temperature, and prestraining of a specimen at room temperature greatly improved the ductility retained at $-78^{\circ} \mathrm{C}$. The ductility of the annealed ingot iron specimens was less at $-154^{\circ} \mathrm{C}$ and $-196^{\circ} \mathrm{C}$ than at room temperature. However, prestraining specimens of annealed ingot iron at room temperature reduced the ductility retained at $-154^{\circ} \mathrm{C}$ and $-196^{\circ} \mathrm{C}$. Moreover, the ductility of specimens of ingot iron in the condition either as annealed, or as quenched and tempered, was about the same at $-78^{\circ} \mathrm{C}$ as at room temperature and prestraining specimens at room temperature had little, if any, effect on the ductility retained at $-78^{\circ} \mathrm{C}$. The effect of prestraining of ingot iron at room temperature on the rheotropic embrittlement of the specimens at lower temperatures apparently depends greatly upon the initial condition of the iron.

\subsection{Cold-Drawn Ingot Iron}

The true stress-strain data obtained in two-stage tension tests with specimens of cold-drawn ingot iron are summarized in figure 9 . These samples of the originally hot-rolled ingot iron had been cold-drawn by the manufacturer to 14 - and 24-percent reduction of area, and were aged at room temperature for several months. The total work hardening during the prestraining in tension at room temperature to a strain of approximately 0.25 of a specimen of ingot iron cold-drawn to 14 percent reduction of area was slightly greater than that of a specimen deformed to the same strain at $-78^{\circ} \mathrm{C}$. The total work harden-

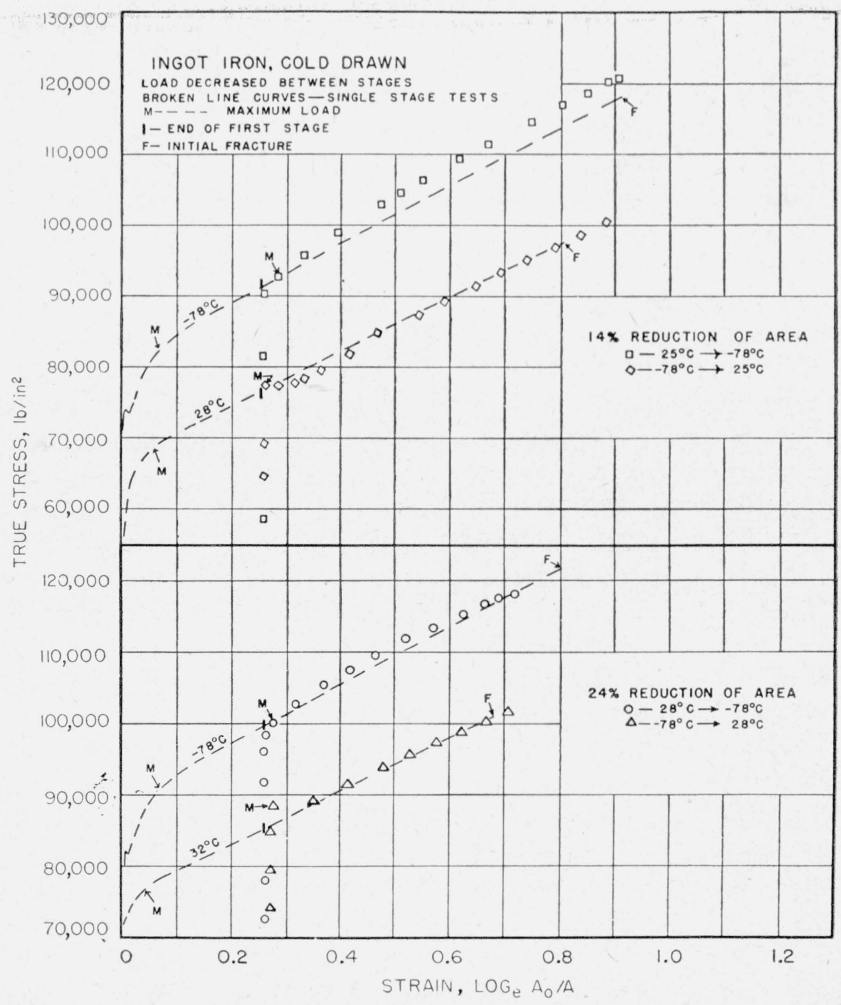

FIGURE 9. True stress-strain values obtained with cold-drawn ingot-iron specimens that were extended in two-stage tension tests at room temperature and $-78^{\circ} \mathrm{C}$. 
ing during the prestraining in tension to a strain of approximately 0.25 at room temperature and at $-78^{\circ} \mathrm{C}$ of specimens of ingot iron cold-drawn to 24 -percent reduction of area was approximately the same as indicated by the coincidence of the true stress-strain values for the second stage of these tests with the true stress-strain curves for the singlestage tests. The degree of strain aging during the deformation in tension of these specimens of the cold-drawn iron was much less than that of the hotrolled ingot-iron specimens due to the prior strain aging that had occurred during the cold-drawing and storage of the iron.

\section{Summary}

A study was made to determine the effect of the strain-temperature history of ingot iron on the true stress-strain relationship for specimens extended in tension at temperatures ranging from $-196^{\circ}$ to $+100^{\circ}$ C. Specimens of annealed, normalized, quenched and tempered, hot-rolled and cold-drawn ingot iron were extended in tension to specified truestrain values at a selected temperature and subsequently extended to fracture at a different temperature. The true stress-strain values obtained in these two-stage tests were compared with those obtained in single-stage tension tests at the same temperatures. The deviation of the true stressstrain curves for the second stage of these tension tests with ingot iron from the true stress-strain curve for a single-stage test at the same temperature generally increases at a decreasing rate as the prestrain of the specimen is increased.

The amount of strain aging and the rheotropic brittleness of specimens of ingot iron vary with the heat treatment and prestrain history of the specimens. The rheotropic brittleness at $-78^{\circ} \mathrm{C}$ or at lower temperatures of normalized or hot-rolled ingot iron is sensitive to and in part curable by prestrain under ductile conditions at higher temperatures; the ductility retained by the specimens in subsequent extension in tension at low temperature is increased. However, prestraining specimens of annealed ingot iron in tension under ductile conditions at room temperature decreases the ductility retained in subsequent extension in tension at $-154^{\circ}$ or $-196^{\circ} \mathrm{C}$.

The work hardening of ingot iron during deformation in tension at temperatures below $-120^{\circ} \mathrm{C}$ is mainly strain hardening, and increases with lowering of the testing temperature. As the temperature is increased above $-120^{\circ} \mathrm{C}$, the influence of the strain aging during the deformation in increasing the total work-hardening rate becomes the predominating factor, and the rate of work hardening increases with increase in testing temperature. The data obtained on the tension specimens of hot-rolled ingot iron indicate that the part of the total work hardening due solely to the strain aging during the deformation to maximum load is considerable at temperatures as low as $-78^{\circ} \mathrm{C}$. Even at $-78^{\circ} \mathrm{C}$ the work hardening due to the strain aging is approximately equal to the increase in strain hardening that occurs as the testing temperature is lowered from $-78^{\circ}$ to $-196^{\circ} \mathrm{C}$. At $+100^{\circ} \mathrm{C}$, the magnitude of the strain aging is at least equal to or greater than the strain hardening.

The data presented in this paper, together with those reported previously [10], show that the strain aging of ingot iron is a verv important factor affecting the true stress-strain relationship at temperatures as low as $-120^{\circ} \mathrm{C}$. Strain aging apparently occurs to some extent at temperatures as low as $-154^{\circ} \mathrm{C}$. These data are contrary to the generally prevailing belief that the strain aging of ingot iron is insignificant at sub-zero temperatures.

The authors are indebted to C. R. Johnson and J. D. Grimsley for assistance in this investigation.

\section{References}

[1] D. J. MeAdam, Jr., G. W. Geil, and R. W. Mebs, Effect of combined stresses and low temperatures on the mechanical properties of some non-ferrous metals, Trans. Am. Soc. Metals. 37, 497 (1946).

[2] D. J. McAdam, Jr., G. W. Geil, and R. W. Mebs, Influence of plastic deformation, combined stresses, and low temperatures on the breaking stress of ferritic steels. Trans. Am. Inst. Mining Met. Engrs. 172, 323 (1947)

[3] D. J. MeAdam, Jr., G. W. Geil, and F. J. Cromwell, Influence of low temperatures on the mechanical properties of 18:8 chromium-nickel steel, J. Research NBS 40, 375 (1948) RP1882.

[4] J. E. Dorn, A. Goldberg, and T. E. Tietz, The effect of thermal-mechanical history on the strain hardening of metals, Trans. Am. Inst. Mining Met. Engrs. 185, 325 (1949).

[5] T. E. Tietz and J. E. Dorn, The effect of strain historie on the work hardening of metals, Trans. Am. Soc. Met. 41A, 163 (1949).

[6] T. E. Tietz, R. A. Anderson, and J. E. Dorn, Effect of prestraining temperatures on the recovery of cold worked aluminum, Trans. Am. Inst. Mining Met. Engrs. 185, 921 (1949).

[7] W. D. Jenkins and T. G. Digges, Influence of strain rate and temperature on the creep of cold-drawn ingot iron, J. Research NBS 43, 117 (1949).

[8] E. J. Ripling and G. Sachs, The effect of strain-temperature history on the flow and fracture characteristics of an annealed steel, Trans. Am. Inst. Mining Met. Engrs. 185, 78 (1949).

[9] W. E. Jenkins and T. G. Digges, Creep of high-purity copper, J. Research NBS 45, 153 (1950) RP2121.

[10] G. W. Geil and N. L. Carwile, Tensile properties of ingot iron at low temperatures, J. Research NBS 45, 129 (1950) RP2119.

[11] E. J. Ripling and W. M. Baldwin, Jr., Rheotropic embrittlement of steel, Trans. Am. Soc. Metals 43, 778 (1951).

[12] G. W. Geil and N. L. Carwile, A reduction-of-area gage for use at low temperatures, J. Research NBS 43, 527 (1949) RP2044.

Washington, February 5, 1952. 